\title{
Technology enhanced learning environments and the potential for enhancing spatial reasoning: a mixed methods study
}

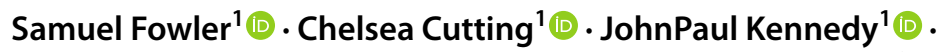

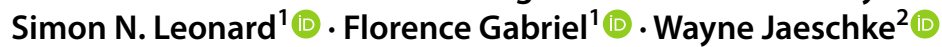 \\ Received: 14 August 2020 / Revised: 21 January 2021 / Accepted: 25 January 2021 / \\ Published online: 24 March 2021 \\ () Mathematics Education Research Group of Australasia, Inc. 2021
}

\begin{abstract}
Spatial reasoning has been shown to be an important, trainable cognitive skillset for developing successful engagement in science, technology, engineering and mathematics (STEM), but little empirical work has been conducted in the context of digitally mediated pedagogies. This paper reports on a study into the effectiveness of a technologically enhanced STEM program on the spatial reasoning of a cohort of year 7 students $(n=107)$. The students undertook five digitally based activities over the period of a week and were assessed on their spatial reasoning development and attitudes towards STEM prior and subsequent to the intervention. Results indicate that the week of learning activities had an impact on attitudes towards STEM and had a positive impact on overall spatial skills. However, no statistically significant improvements were found within the spatial sub-skills or in relation to specific activities.
\end{abstract}

Keywords Educational technology $\cdot$ Spatial reasoning $\cdot$ Middle school education . Technology enhanced learning environments $\cdot$ STEM $\cdot$ Student attitude

\section{Introduction}

An educational priority of many countries is to provide children of all ages with experiences that promote and develop the interdisciplinary concepts within science, technology, engineering and mathematics (STEM) to better prepare young people to possess the cognitive skills required to enter STEM careers (Bruce et al., 2016; Lowrie \& Jorgensen, 2018). A key component to successful engagement in STEM is the ability to think and reason spatially. Spatial reasoning has gained enormous attention within the field of mathematics education since the 1970s. However,

Samuel Fowler

Sam.Fowler@unisa.edu.au

Extended author information available on the last page of the article 
the increasing interest from the fields of cognitive neurosciences, mathematics, psychology and philosophy across all age, sex and demographic groups illustrates the transdisciplinary and universal nature of this skillset (Bruce et al., 2016; Lowrie \& Jorgensen, 2018). The diversity of this skillset is evident in the way humans as embodied, situated beings (Lakoff \& Núñez, 2001) interact between spatial models of objects, spatial relations between objects, or exploring the spatial coordinates of places and spaces (Uttal et al., 2013). For example, locating, orienting, decomposing/ recomposing, balancing, patterning diagramming, navigating, comparing, scaling, transforming and seeing symmetry (Bruce et al., 2016) are all skills that engage our spatial reasoning abilities; however, they are not constrained to a particular context or discipline.

In acknowledging the transferability and affordances spatial reasoning provides in a wide range of everyday contexts, significant attention has been dedicated to exploring the prevalence of and advantages that spatial reasoning plays in the STEM domains of learning. Wai et al. (2009) examined this connection in an analysis of longitudinal research on spatial reasoning and STEM education, spanning 50 years. The findings report that spatial abilities are influential in the STEM domains at school and well beyond. That is, those students who possess strong spatial reasoning skills not only achieve greater success in STEM-based learning opportunities but are also more likely to enter a STEM-based career once they leave school. Despite these findings of the positive impact spatial reasoning can have on achievement in the STEM fields, relatively little is understood about the relationship between spatial activities incorporated into STEM learning designs and knowledge, skills and dispositions developed by children undertaking them (Cutting, 2019; Stieff \& Uttal, 2015; Mulligan et al., 2017).

The study presented in this paper will respond to this gap in knowledge about the relationship between spatial learning design and knowledge, skill and disposition development by investigating the impact of a week-long, school-initiated program of spatial activities conducted within a Technology Enhanced Learning Environment (TELE). The TELE in use is an example of the kind of spaces being commissioned by many schools and school systems in Australia (see for example South Australia Department for Education, 2020), as in other parts of the world (Community Research and Development Information Service (CORDIS), 2020), generally in the form of dedicated 'STEM' buildings. This move follows a similar investment in so-called next-generation learning spaces in many higher education campuses around the world (Matthews et al., 2011; Leonard et al., 2017). At both levels of education, these spaces tend to reify a distinctly constructivist/social constructivist understanding of learning in their promotion of student led-and typically collaborative-problem solving. This student centric focus of TELEs is reflected in the use of collaborative areas for laptop usage; the use of advanced computer pools with floor space for experimentation with robots; podcasting equipment for student voice; a $360^{\circ}$ room for class immersion and VR for individual experiences; and advanced 3D printers for students to actualise their digital creations.

Despite some now dated reviews (Scottish Funding Council, 2006; Blackmore et al., 2011), research on the impact of these spaces remains nascent. Indeed, there is a strong sense in the literature that the dominant narratives of 'twenty-first century change' 
vastly outweigh the empirical evidence as a basis for this investment (see for example Carvalho \& Yeoman, 2018). Within the empirical work that does exist, though, there is a strong suggestion that the relationship between the learning space and any changes in learning is complex. Waldrip et al. (2014), for example, found that the connection between student performance and a 'next-generation' learning space seemed to be mediated by impacts on student well-being. Accounting for these complex effects is of increasing interest to educational researchers (Woolcott et al., 2016; Leonard et al., 2017). It is also an important influence on the design of the present study in which we have adopted a multi-phasic research design to begin to capture changes in both spatial skills and in student attitudes and disposition. This study considers the learning space 'in the wild', so to speak, and adopts a multi-phasic design in order to learn about the learning taking place in TELEs as operated by teachers in their normal practice rather than within the confines of a controlled experiment. Before we return to the detail of the study design, we will complete this introduction with a discussion of some key elements of spatial reasoning and student attitudes to STEM.

\section{Aspects of spatial reasoning}

Spatial reasoning can be considered as a meta term for a set of important cognitive skills that involve the understanding and engagement with three main components: the first is an awareness of spatial concepts such as distance and dimensions; the second is the processes and tools that learners engage with when decoding information such as external representations; and the third constitutes the reasoning and decision making required to understand the problem contexts and data sources (Carroll, 1993; Lowrie et al., 2019; National Research Council, 2006). Spatial reasoning is often ill-defined within the relevant literature and used interchangeably with terms such as spatial thinking, spatial abilities and visual spatial reasoning. Despite these ambiguities in terminology, research from the fields of psychology and education generally agree that spatial reasoning describes an 'ability to generate, retain, retrieve, and transform well-structured visual images’ (Lohman, 1996, p. 97). As Battista (2007) describes, it is 'the ability to see, inspect, and reflect on spatial objects, images, relationships and transformations' (p. 843). This study, however, is not concerned with defining or re-defining what constitutes a spatial ability. Rather, we are interested in what affordances technology may provide in developing children's spatial skills. We therefore take the theoretical position of a three-tier framework for articulating the core components of spatial reasoning (Ramful et al., 2017). The three components to this framework are mental rotation, spatial visualisation and spatial orientation and serve as the spatial reasoning abilities our study will explore (Linn \& Petersen, 1985).

\section{Mental rotation}

As the name suggests, mental rotation is the cognitive process which involves imagining what a 2D shape or 3D object may look like after it has been turned by a specific angle (Shepard \& Metzler, 1971). Two mental rotation paradigms 
are primarily used in the literature to describe the way in which mental rotation is distinguished. The first is concerned with perspective tasks, which require the participant to determine how an object would appear from a different viewpoint; for instance, mentally rotating a 3D structure to consider what it would look like if rotated $90^{\circ}$. The second paradigm describes comparison tasks, which are concerned with changes to the object itself, rather than the change in position or perspective of the participant. The aim here, therefore, is to determine whether pairs of visual stimuli presented from two different perspectives are in fact congruent or mirror images (Guillot et al., 2012).

\section{Spatial visualisation}

Spatial visualisation has been recognised as a process or skill that is a core spatial reasoning construct, and vital for understanding and engaging in STEM (Arcavi, 2003; Ontario Ministry of Education, 2008; Ramful \& Lowrie, 2015). Spatial visualisation is one of the most complex categories to define in the broader landscape of spatial reasoning. As the term itself is categorised in many ways, it is often criticised because of its lack of specificity (Uttal et al., 2013). Linn and Petersen (1985) defined spatial visualisation as a multi-step manipulation of objects. That is, performing multiple rotations and transformations of objects mentally may occur whilst the participant keeps a mental record of each application and its impact on the original image at hand. Two common instruments used to measure this ability are the Paper Folding Test and the Form Board Test (Ekstrom et al., 1976), which require participants to imagine a series of spatial transformations (Lowrie et al., 2019). Spatial visualisation is also described as the generation, retention, retrieval and manipulation of spatial properties of these imagined objects (Lowrie et al., 2019), and is also referred to as thinking with the 'mind's eye' (Ontario Ministry of Education, 2008). The common thread between these definitions is the multi-step nature of the manipulations and transformations held in one's mind.

\section{Spatial orientation}

As the third spatial reasoning ability of focus in this study, spatial orientation differs from the close relationship between the former two abilities described, in that spatial orientation does not require the participant to mentally move an object; rather the perceptual perspective of the participant viewing the object is changed or moved (McGee, 1979; Tartre, 1990). Unlike the perspective tasks for mental rotation described above, spatial orientation requires the participant to regulate their own orientation or posture in relation to the surrounding environment. That is, it requires the participant to mentally navigate pathways through space to make sense of and interpret visual representations of the objects in such spaces-such as maps (Connor \& Serbin, 1980; Pietropaolo \& Crusio, 2012). 


\section{Developing spatial reasoning}

By partnering with a school which was invested in assessing the educative effectiveness of their new technologically enhanced learning space, this study aimed to examine how lessons within this new environment effected students spatial reasoning development. Researchers consistently identify digital tools, such as dynamic geometric environments (Sinclair et al., 2016), 3D printing (Cochran et al., 2016), virtual reality (Ulan et al., 2018, Leonard and Fitzgerald, 2018) and games such as Minecraft (Andrus et al., 2020, Fowler et al., 2019), as effective developers of spatial reasoning. Despite the significant development of these educational technologies and the many papers which suggest digital tools as effective conduits for developing spatial reasoning (see for example Attard et al., 2020; Lowrie \& Logan, 2018; Venturini \& Sinclair, 2017), little actual empirical work has been conducted. Also of interest was the clarification of which spatial skills and subskills were specifically developed through the use of computer aided design programs and robotics. The development of these important cognitive skills has obvious benefits for student's successful achievement at school (Cheng \& Mix, 2014; Woolcott et al., 2020) and is integral to those seeking to enter STEM careers (Uttal et al., 2013; Sorby \& Panther, 2020).

\section{Technologically mediated forms of spatial reasoning development}

The integration of technology into the contemporary classroom is increasingly prevalent and can allow students to explore a range of interdisciplinary concepts and spatial reasoning skills. For example, in an experimental study exploring the role interactive enabled virtual environments, animated (observational) virtual environments and conventional (pen and paper) training had on high school students' spatial visualisation skills, both the virtual groups made gains significantly higher than the control group (Rafi et al., 2008). Many studies have emphasised the importance of applying appropriate learning aides (manipulatives) and experiences to the classroom (Lieban \& Lavicza, 2019) in the development of conceptual ideas and spatial skills. However, the accessibility to technology schools are now experiencing means we need to reconsider what physical materials, resources and experiences we can utilise for authentic learning experiences. This is particularly prescient to modern theories of embodied learning (Leonard \& Fitzgerald, 2018) which emphasise the diagrammatic and gesturally congruent movements of digital tools as a means to engage spatial reasoning in ways that have previously been impossible (Johnson-Glenberg, 2019).

In the context of the activities explored in this study, the use of computer-aided design (CAD) programs and $3 \mathrm{D}$ printing have shown promise in the effective exploration properties of 3D shapes (see for example Cochran et al., 2016; Lieban \& Lavicza, 2019; Singer \& Shafer, 2018). The virtual manipulation, segmentation and combination of objects, whilst developing pre-visualised objects for printing, engages students in the types of problem solving important to the development of 
spatial reasoning (Harris et al., 2020). Likewise, coding robots offers a powerful method for posing rich spatial problems (Sebena, 2017; Francis et al., 2015) and therefore, encourages them to perform spatial visualisations, especially in path based spatial subskills such as spatial orientation (Harris et al., 2020).

\section{Student attitudes towards STEM}

Declining enrolments in the STEM disciplines, particularly in science and mathematics, have been a concern in Australia for over 30 years (see for example Dekkers \& de Laeter, 2001; Dekkers et al., 1986; Kennedy et al., 2014; Kennedy et al, 2018). Central to forming an understanding of these has been the concept of student attitudes towards school STEM courses, with the premise that positive attitudes towards STEM leads to increased enrolments in these subjects and hence greater exposure to many of the unique learning experiences and focussed critical thinking skills associated with these subject areas. In particular, as elucidated by the learning context of this study, these STEM disciplines are ideally placed to develop skills in spatial thinking.

However, attitudes are not a unidimensional construct and students do not form attitudes towards one subject area in isolation from their other subjects (see Kennedy et al., 2016). It is therefore appropriate in this context to consider how a student's attitudinal profile develops and changes in response to learning activities such as those described in this study. Kennedy et al. (2016) describe a student's attitudinal profile in terms of seven attitudinal factors: perceived difficulty, enjoyability, career intentions, relevance, self-efficacy, career usefulness and personal usefulness. In addition to developing a students' spatial reasoning skills, we predicted that the learning activities used in this study would also enhance the students' self-ratings of relevance, self-efficacy and enjoyability towards science and mathematics as studied at school as well as counter some of the blockers introduced by high levels of perceived difficulty and low levels of personal relevance.

Ways of exploring and measuring the complex cognitive and affective changes resulting from the establishment of a new TELE became a key focus of this project. This exploratory project worked as a pilot within the context of the participant school with the aim of developing the school's capacity to measure the impact of their planned interventions through multiple dimensions.

\section{Method}

\section{School context}

The participants were students from two campuses within a multi-campus PreschoolYear 12 College. Situated in an outer-metropolitan location, this very large co-educational school services a mixed demographic that is broadly representative of the wider Australian population. 
At the time of the study, the college had recently opened a central TELE to be used by students from all campuses, known as The Innovation and Creativity School (TICS). As schools begin to utilise TELEs, they make compromises which balance factors such as educational effect, equity and staffing. The common use of this facility between the different campuses had led to an initial learning design involving what were, in effect, week-long excursions to TICS. That is, students worked on various projects within the TICS building for a week instead of their regular class activities, with classes from the different campuses of the college rotating through the space. The decisions made by the participant school are quite typical of TELE implementation and, as the study sought to explore real world implementation, these choices affected the structure of the study. The timing of visits to TICS is shown in Table 1.

This study also took place in the midst of the early stages of the COVID-19 pandemic and was suspended for some time due to related school closures. The impact of this disruption is unclear, but for some students in the study the time at TICS represents the majority of their face-to-face school for some weeks, with the rest of their learning moving to online engagement from their homes. Future research is likely to show more about the impact of this disruption.

\section{Participants}

Two groups of year 7 students (12-13-year-olds) were involved in a week (15 h in total) of rotational tasks using technologically mediated pedagogies designed and facilitated by staff from the school. Group 1 consisted of 18 girls and 16 boys, while group 2 included 32 girls and 41 boys. Ethics approval was sourced from University of South Australia and the school. Written consents from parents were obtained before the videoing and analysis stage.

The two groups fulfilled different roles in the study due to logistical issues at the participant school beyond the control of the researchers. Within this paper, group 1 was used to show the effect of a week of learning experiences in the TICS on their spatial reasoning. This group's assessments of attitude towards STEM also acted as a post-visit benchmark as they attended TICS prior to the attitude surveys being conducted. The larger group, group 2, were assessed for the effects of specific activities on spatial reasoning and how a week at the TICS affected their views of the STEM subjects. This group's activities were also videoed and behaviour coded to explore the effect of pedagogical choices on spatial reasoning.

\section{Lessons}

All lessons were conducted by digital technology teachers working in the TICS. The students participated in five technologically themed activities over a week: GPS in sport, webpage design, creative digital storytelling, 3D modelling and robotic engineering.

The tasks identified to have the most potential for engaging in spatial reasoning were the $3 \mathrm{D}$ modelling-due to the focus on virtually rotating, splitting and 


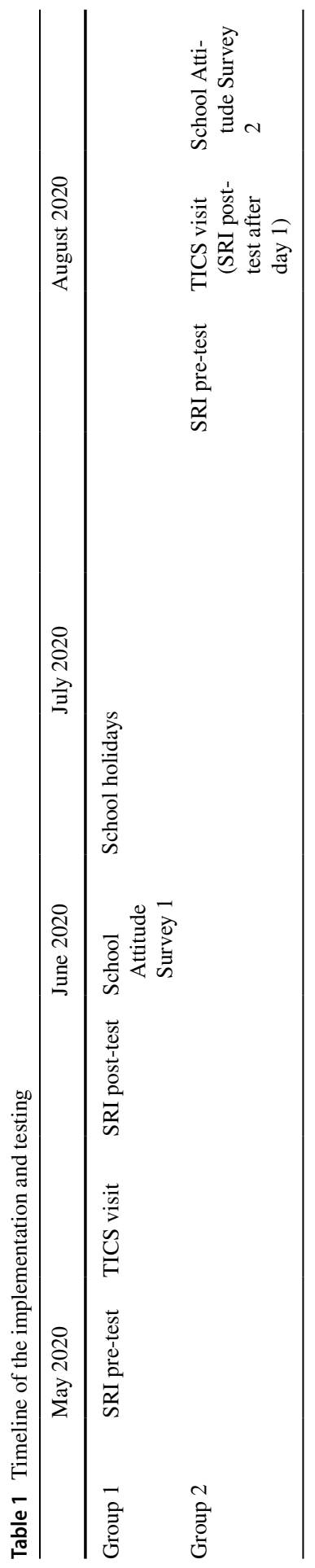


combining 3D objects - and Robotic Engineering with its focus on navigation. Whilst the GPS in sport included some consideration of spatial orientation, it was more focussed on data analysis. It was hypothesised that this activity may not have improved spatial reasoning past what would normally be developed in a regular physical education lesson. However, the handling of real data in this activity was hoped to improve students' attitudes towards the relevance of mathematics outside of the classroom.

The 3D modelling activity examined the elements of spinning-tops that lead to them spinning for the longest time such as where the majority of the weight was positioned or the negative effects of asymmetry. After some time experimenting with some example tops and learning TinkerCAD skills, the students used their analysis of the experiments to design their own tops which were later printed on a 3D printer and tested for effectiveness (see Fig. 1 as an example).

The robotic engineering lesson introduced the students to advanced block coding using 'mBots'. These robots are coded to move at various angles and use advanced sensors to measure distances and aspects of tilting. Throughout the day, students were challenged to tasks of increasing complexity using their knowledge of abstraction, algorithms, simulation and evaluation.

The GPS in sport session used trackers during an outdoor physical session to provide data for excel analysis relating to concepts such as top speed, speed zones and distance travelled. The webpage design lessons explored how to create a webpage using the underlying code whilst the digital innovation and creativity course used Adobe Spark to develop a persuasive text using storytelling features and the fundamentals of visual design.

\section{Spatial reasoning testing materials}

Ramful et al. (2017) developed and validated the spatial reasoning instrument (SRI) to measure the spatial reasoning of 11-13-year-old students. This paper-and-pencil

Fig. 1 A spinning top design in TinkerCAD

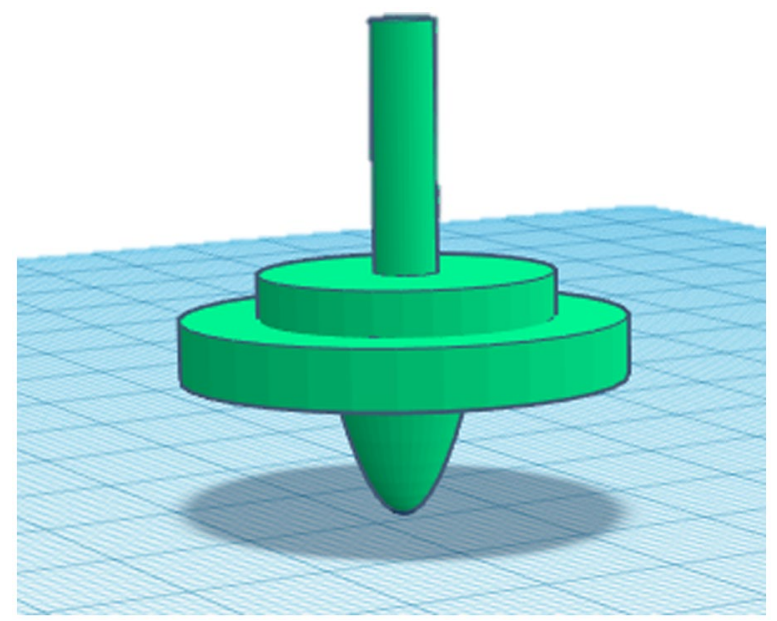


test, developed from the extensive psychological literature, identifies three spatial skills: spatial orientation, spatial visualisation and mental rotation. Mimicking national testing regimes, such as Australia's NAPLAN, the SRI has 30 multiple

a

The diagram below represents the net of a box.

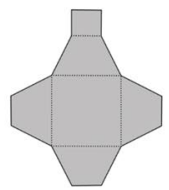

Which one of the following figures represents the box when the net is folded?
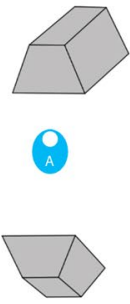

(c) b

Kate and William's seating positions are shown below.

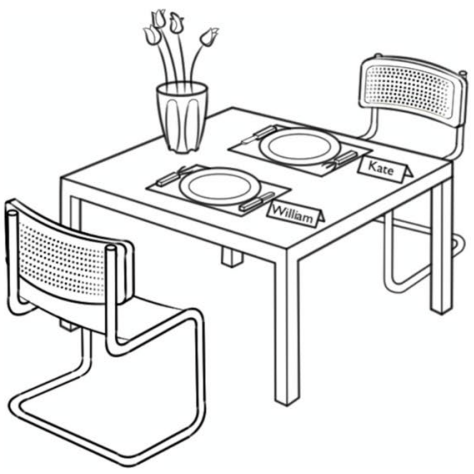

In which position is the flower vase from Kate's view?

To her right.

To her left.

C The figure shown below is rotated by one quarter turn anticlockwise.

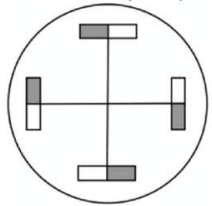

Which of the following shows the result of the rotation?
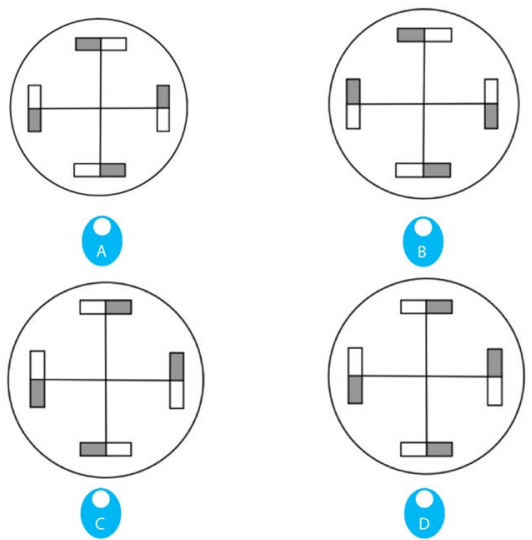

Fig. 2 Example test item from the SRI for spatial visualisation, spatial orientation and mental rotation 
choice questions based on images or diagrams with minimal written instruction (examples below in Fig. 2).

The SRI was used prior to the students attending the week of learning activities (see Table 1). Group 1 completed the post-tests after the week of activities in order to assess the overall contribution of the week's activities to their spatial reasoning. Group 2 completed the post-tests after they had completed 1 day of their activities. In this way, the less spatial activities-GPS in sport, webpage design and creativity and digital storytelling - could act as controls to the more spatially based activities. Neither group received their pre-test scores prior to the post-test in order to mitigate memory effects and only students whose parents had provided consent were included in the analyses.

\section{Affective assessment materials}

The research team are involved in an ongoing project with the school to measure students' changing attitudes towards their subjects over time which makes use of the School Attitude Survey (SAS) instrument. This research tool expands on the one developed by Kennedy (2016) by adding two additional attitudinal factors, subject anxiety and creativity, to the existing seven described previously. The SAS measures students' self-reported attitudes towards all of their curriculum subjects using a digital online tool. Students move on-screen sliders like the example in Fig. 3 to rate their relative agreement with specific statements for each of their subjects. This effectively results in an analogue scale from -50 to +50 for each attitudinal factor for each subject. By calculating a mean rating for each attitudinal factor across all subjects, a student's composite attitude rating (CAR) is generated. This CAR can then be subtracted from that student's ratings for each subject in turn to generate

\section{School Attitudes}

Project

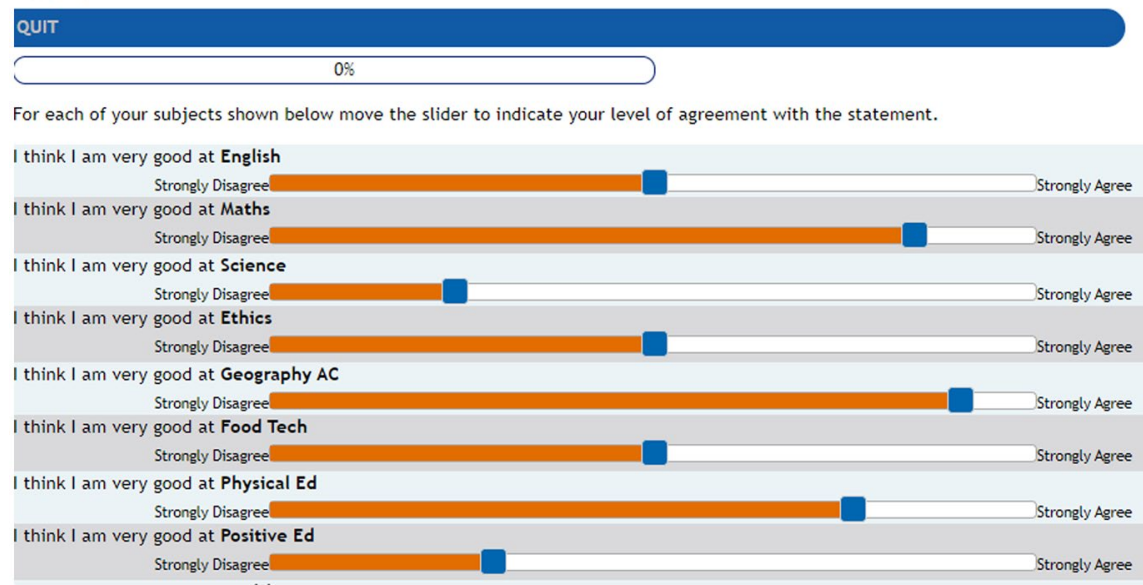

Fig. 3 Screenshot of the school attitudes survey 
a Subject Attitude Rating (SAR). The SAR is therefore a student's relative attitude rating for a particular subject in comparison to their attitude rating to school in general. This approach allows for individual subjects or the separate attitudinal factors to be compared between groups of students without the need for a universally agreed upon definition of neutral attitude (see Kennedy et al., 2016 for detailed explanation).

Data from the SAS were used to assess any affective changes to students' attitudes over the week of activities. Due to administrative reasons, group 1 attended TICS prior to the SAS measurement point. Therefore, attitude data from group 1 acts as a post-visit benchmark of student attitudes. The SAS was administered to group 2 before and after their visit to TICS (see Table 1). Therefore, these data allow the impacts of the full week of activities on students' attitudes to be measured.

\section{Video coding with new coding protocol}

In order to examine the actions which may promote spatial reasoning, the activities of 3D modelling and robotics engineering were selectively filmed and coded with an observation protocol adapted from Smith et al. (2013) 'Classroom Observation Protocol for Undergraduate STEM' (COPUS). Additions to COPUS included specific spatial reasoning actions (e.g. estimating measurements, using gestures to indicate rotation, computer-based movements which split or combine an object), use of technology, experimentation and advanced problem posing.

The videos were analysed using 'Interact' software which allows for continuous and concurrent coding and then the subsequent creation of visualisation timelines and statistical data.

\section{Results}

\section{Pre-tests}

An independent-samples $t$ test was conducted to compare female spatial reasoning pre-test scores to male spatial reasoning pre-test scores for both groups. In group 1, there was no significant difference between the scores for female spatial reasoning pre-test scores $(M=17.1, S D=5.1)$ and male spatial reasoning pre-test scores $(M=17.7, S D=4.8)) ; t(32)=0.731, p=0.73$. In group 2 , there was also no significant difference between the scores for female spatial reasoning pre-test scores $(M=18.6, S D=5.7)$ and male spatial reasoning pre-test scores $(M=18.6$, $S D=6) ; t(71)=0.195, p=0.85$. An independent-samples $t$ test showed that there were no significant differences in spatial reasoning skills between group 1 $(M=17.50, S D=4.88)$ and group $2(M=18.66, S D=5.84)$ prior to the visit to TICS $(t(105)=1.00, p=0.25)$.

A repeated measures ANOVA was conducted to identify relative differences in the means of the individual spatial subskills in the pre-test for both group 1 and group 
2 combined (as independent-samples $t$ tests did not show any significant differences between the schools' means for each subskill). The results show that there was a small but statistically significant difference in the individual subskill scores $F(2$, $212)=141.73, p<0.01, \eta_{p}{ }^{2}=0.24$. Spatial Orientation scores were significantly greater than Mental Rotation scores $(t(106)=10.95, p<0.001)$ which were found to be significantly greater than Spatial Visualisation scores $(t(106)=5.70, p<0.001)$.

\section{Post-tests}

A two-way ANOVA for repeated measures (three subskills: mental rotation, spatial orientation and spatial visualisation by two measurement times: pre and post) was conducted on each group separately to examine the effect of the visit to TICS on students SRI total scores and subskill scores. Results from the two groups are displayed in Table 2 .

There was a significant difference between the scores on pre- and post-tests for group 1 (mean difference $=0.68, F(1,33)=15.28, p<0.001, \eta_{p}{ }^{2}=0.32$ ). There was also a significant difference between subskills $(p<0.001)$; the means of each subskill were all significantly different from each other $(p<0.005)$. Overall, the group 1 showed a large improvement in SRI total scores after a week of technologically rich activities, but there was no statistically significant difference between the growth shown in any particular subskill.

The results of group 2 showed that there was a large and statistically significant difference between subskills $\left(F(2,136)=125.8, p<0.001, \eta_{p}{ }^{2}=0.65\right)$; the means of each subskill were all significantly different from each other $(p<0.005)$. However, there was no significant difference between the subskill scores on pre- and posttests $\left(\right.$ Mean difference $\left.=0.72, F(2,136)=0.52, p=0.59, \eta_{p}{ }^{2}=0.008\right)$. This indicates that whilst the participants generally scored better on certain spatial subskills (such as spatial orientation) than others, their participation in any one activity did not significantly improve any specific spatial skill. The interaction between total spatial reasoning score and pre- and post-tests was also not significant suggesting that the time of exposure to the activity may have been insufficient.

Before visiting the TICS the second group was divided into a number of classes. These classes each did a different activity on the first day and their results

Table 2 Mean scores and standard deviation in individual subskills and total spatial reasoning for group 1 and group 2

\begin{tabular}{|c|c|c|c|c|}
\hline \multirow{3}{*}{ Subtest (max score) } & \multicolumn{2}{|l|}{ Group 1} & \multicolumn{2}{|l|}{ Group 2} \\
\hline & \multicolumn{2}{|c|}{ Mean score (standard deviation) } & \multicolumn{2}{|c|}{ Mean score (standard deviation } \\
\hline & Pre-test & Post-test & Pre-test & Post-test \\
\hline Mental rotation (10) & $5.24(2.31)$ & $6.01(2.40)$ & $5.94(2.52)$ & $6.32(2.64)$ \\
\hline Spatial orientation (10) & $7.94(1.65)$ & $8.26(1.56)$ & 8.03 (1.99) & $8.26(1.86)$ \\
\hline Spatial visualisation (10) & $4.32(2.10)$ & $4.71(2.15)$ & $4.70(2.37)$ & $4.81(2.48)$ \\
\hline Total (30) & $17.50(4.88)$ & $19.09(5.20)$ & $18.65(5.87)$ & $19.38(5.94)$ \\
\hline
\end{tabular}


Table 3 Mean scores and standard deviation on pre-test and post-test by individual activity from group 2

\begin{tabular}{lllll}
\hline & Group & & Mean total score & Std. deviation \\
\hline \multirow{2}{*}{ Spatial activities } & \multirow{2}{*}{ 3D modelling } & Pre-test & 20.25 & 6.94 \\
& \multirow{2}{*}{ Robotic engineering } & Post-test & 20.94 & 6.16 \\
& & Pre-test & 19.14 & 4.80 \\
Non-spatial activities & \multirow{2}{*}{ Website design } & Post-test & 19.50 & 5.87 \\
& & Pre-test & 17.85 & 4.88 \\
& \multirow{2}{*}{ GPS and sport } & Post-test & 19.15 & 4.30 \\
& & Pre-test & 19.00 & 7.19 \\
& \multirow{2}{*}{ Creative digital storytelling } & Pre-test & 17.00 & 6.43 \\
& & Post-test & 17.81 & 4.99 \\
& & & & 6.75 \\
\hline
\end{tabular}

are shown in Table 3. A two-way ANOVA for repeated measures was conducted to examine the effect of the type of specific activity on SRI scores (five learning activities: 3D modelling, robotic engineering, GPS and sport, webpage design and creative digital storytelling by two measurements times: pre and post). There was no significant difference between the activities in term of development between pre and post-tests $(F(4,68)=0.14, p=0.97)$. There was no significant difference between learning activity groups development between tests in any particular subskill $(F(8,136)=0.66, p=0.73)$.

\section{Affect}

As outlined previously, attitudes are not unidimensional and so differing aspects need to be considered when analysing the effect of the visit to TICS on student affect. Several comparative analyses are worthy of investigation. Firstly, is there a change in attitudes towards school in general seen in the group 2 pre- and postattitude profiles? Figure 4 shows some small variation in the differing aspects of the composite attitudinal profiles; however, a one-way repeated measures ANOVA did not reveal any statistically significant differences between the attitudinal profiles of group 2 before and after their visit to TICS. A Wilcoxon rank sum test was used to identify any differences in the attitudinal profiles between group 1 (measured a number of weeks after their visit to TICS) and group 2 post (measured immediately after their visit to TICS). This non-parametric test was utilised to compare the two groups as the assumption of equal variance, required for an independent samples Student's $t$ test, was not supported by the sample. No statistically significant differences between the two profiles were identified. This is to say that the CARs of group 1 students after their visit to TICS were statistically similar to the CARs of group 2 students after their visit even though these visits were measured around 6 weeks apart.

Secondly, is there a change in attitudes towards mathematics or science seen in the group 2 pre- and post- attitude data? Figure 5 shows what appear to be some small positive changes in attitude between the two testing points in particular in regard 


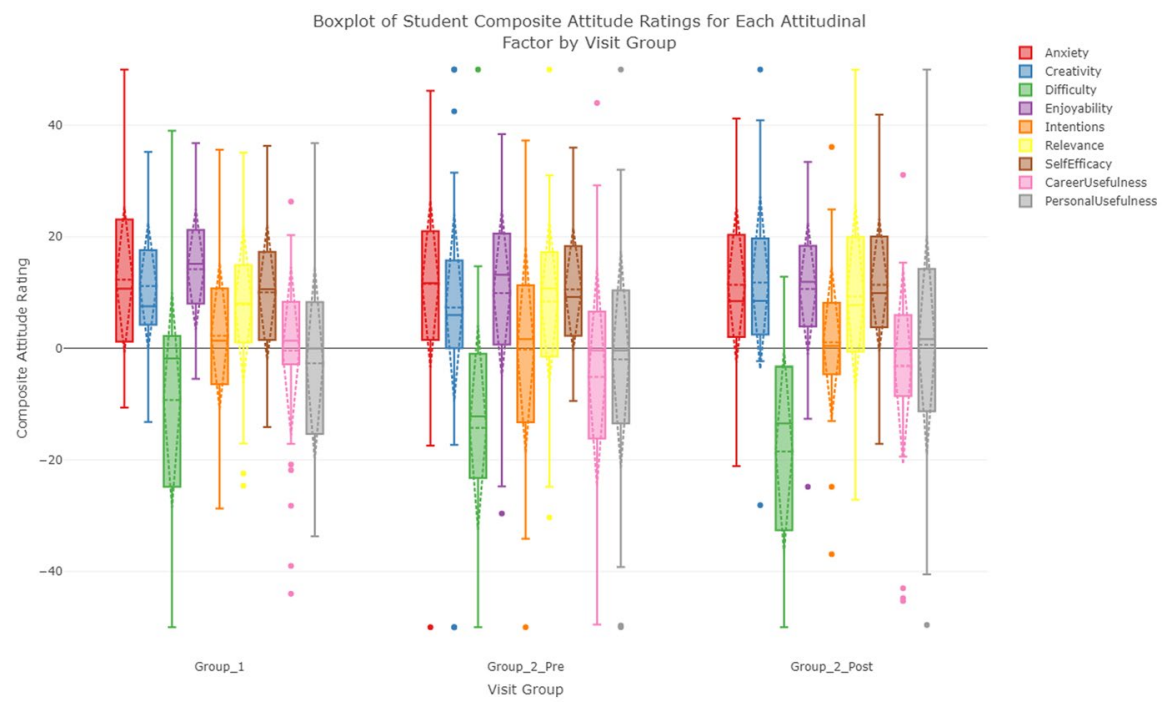

Fig. 4 Boxplot of student composite attitude ratings towards school subjects

to creativity, self-efficacy and career usefulness in mathematics. Again, a one-way repeated measures ANOVA was used to compare the profiles of group 2 pre- and post-visit to TICS. However, this revealed no statistically significant changes in students' attitude ratings towards mathematics at the $p<0.05$ level between the pre- and post-measurements for the attitudinal factors of creativity $(F(1,83)=1.39, p=0.24)$, self-efficacy $(F(1,83)=1.59, p=0.21)$, or career usefulness $(F(1,83)=0.14, p=0.71)$.

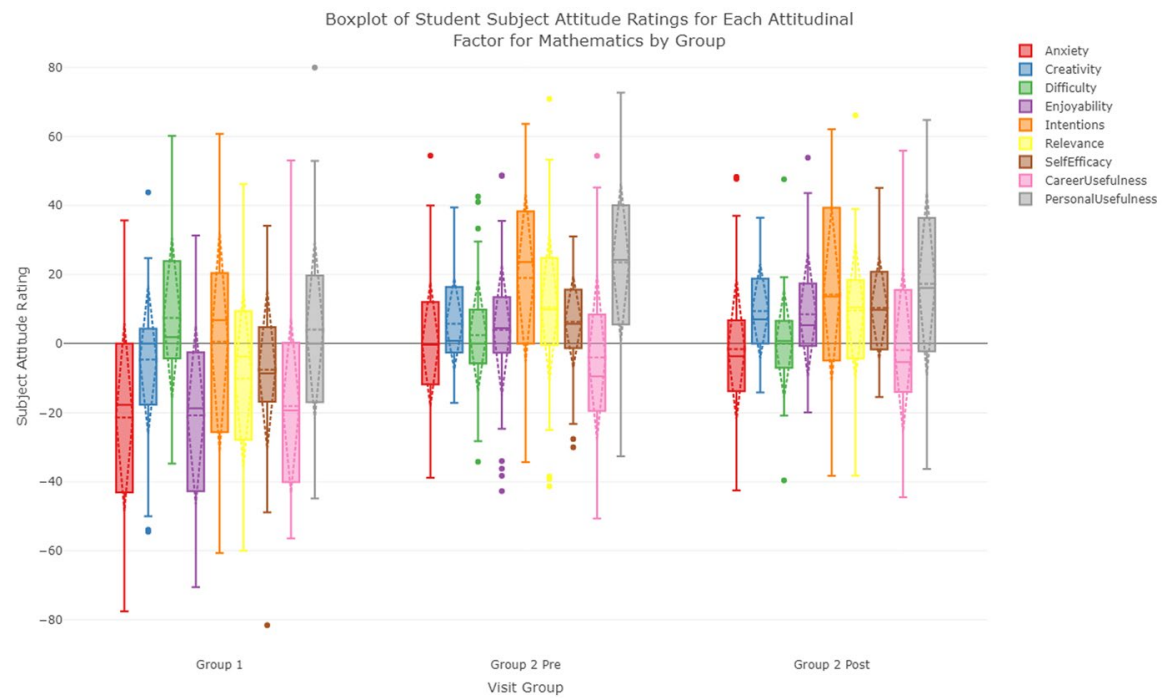

Fig. 5 Boxplot of student attitude ratings towards mathematics for selected attitudinal factors 
Table 4 Statistically significant differences in the attitudinal profiles for Mathematics between group 1 and group 2 post-visit to TICS

\begin{tabular}{lcccr}
\hline Attitudinal factor & Group 1 median & $\begin{array}{l}\text { Group 2 median SAR } \\
\text { post-visit }\end{array}$ & Wilcoxon $W$ & $p$ \\
\hline Creativity & 0.00 & 6.98 & 329 & 0.004 \\
Enjoyability & -18.70 & 5.27 & 196 & 0.001 \\
Relevance & -3.85 & 10.50 & 303.5 & 0.002 \\
Self-efficacy & -8.55 & 9.71 & 351.5 & 0.010 \\
Personal usefulness & 0.00 & 16.10 & 373.5 & 0.020 \\
\hline
\end{tabular}

A Wilcoxon rank sum test was then used to compare the attitudinal profiles of group 1 (measured a number of weeks after their visit to TICS) and group 2 post (measured immediately after their visit to TICS). This test revealed a number of statistically significant differences in the attitudinal profiles for mathematics between group 1 and group 2 post-visit to TICS, and these are shown in Table 4. The SARs of group 2 students for mathematics were statistically greater than the attitudes of group 1 students post visit across five attitudinal factors.

Figure 6 shows the attitudinal profile of these same groups of students towards their science classes. A one-way repeated measure ANOVA revealed no statistically significant differences between the pre- and post-attitudinal profiles of group 2. Again, a Wilcoxon rank sum test was used to compare the attitudinal profiles of group 1 and

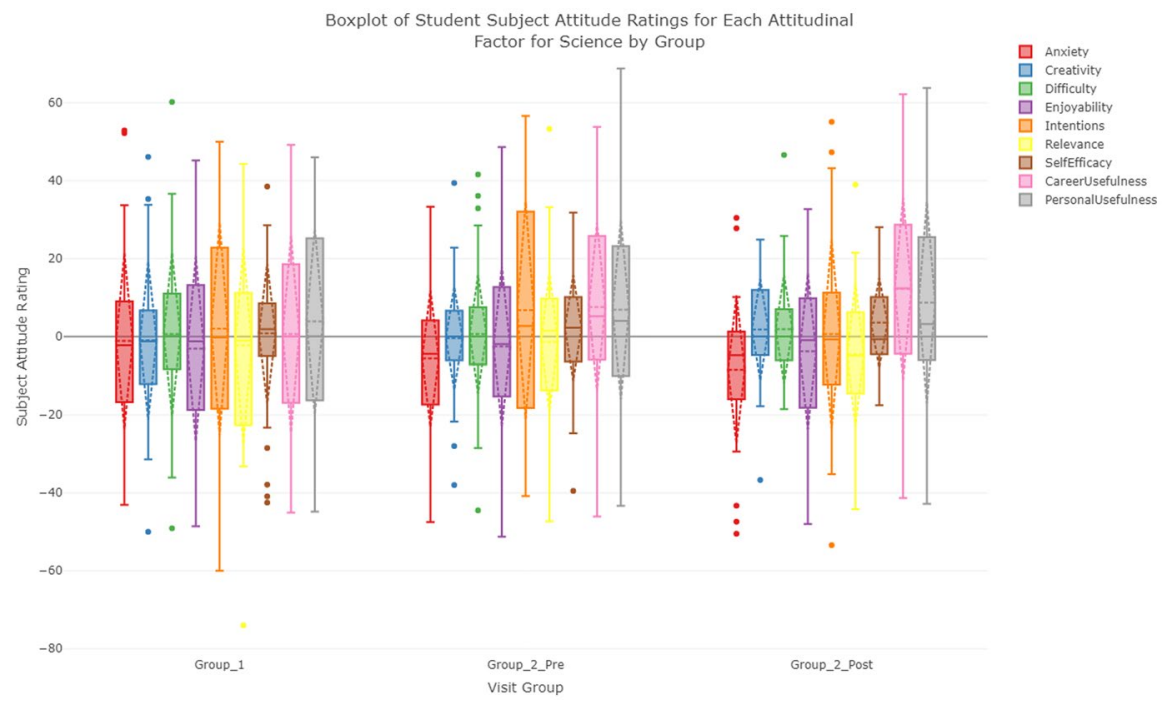

Fig. 6 Boxplot of student attitude ratings towards science for selected attitudinal factors 

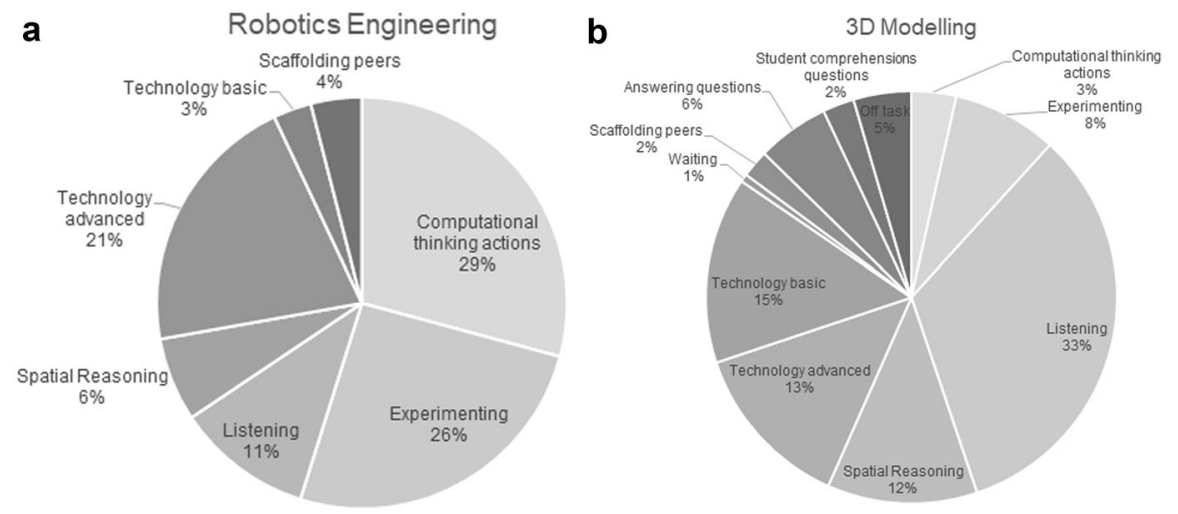

Fig. 7 Percentage of codes for students' actions from sampled sections of robotics engineering and 3D modelling

group 2 post-visit to TICS. No statistically significant differences in the attitudinal profiles for science were found.

\section{Video}

Analysis of the video of the 3D modelling and robotic engineering lessons demonstrated that spatial reasoning was not actually the main focus of the tasks being undertaken, as seen in Fig. 7. In the 3D modelling lesson, the coding showed that $33 \%$ of the students' actions were related to listening compared to $11 \%$ being involved in actions which demonstrate spatial reasoning. The robotic engineering session involved much more experimentation (26\% compared to $8 \%$ in 3D modelling) but seemed to have a higher focus on computational thinking (29\% of student actions) compared to spatial reasoning (6\% of student actions).

In both classes, teachers attempted to get the students working autonomously whilst they provided individual guidance $(67 \%$ of teacher's time in robotics engineering and $48 \%$ in 3D modelling) but the CAD program and the tight parameters of the 3D modelling instructions reduced the amount of time the students were involved in inquiry type tasks.

\section{Discussion}

One of the primary goals of the study was to ascertain if spatial reasoning skills could be developed by learning in a TELE. Whilst early results for group 1 were positive, it is difficult to confidently identify which particular actions led to these results. The results of group 2 used controls but failed to show that any specific activity had a significant effect on SRI scores. The shortened time period between measurements for this second group likely affected the results, as students had only 
had one day of using the technology before the SRI measurement was conducted. Further research is required on the effects of extended periods of computer aided interventions.

Interesting results emerged from the comparisons of the pre-tests and post-tests. Whilst recent research has shown significant differences in male and females spatial reasoning ability (see Logan \& Lowrie, 2017; Reilly et al., 2017), no such pattern emerged in this study for either group of participants. This may be a result of the structure of the spatial reasoning instrument itself as similar results were seen when Lowrie et al. (2018) used the SRI in their larger study, but further investigation is warranted.

Another aspect of the study which may be influenced by the spatial reasoning instrument is the substantial difference between the individual subskills scores in both groups. Using the pre-test scores, it is evident that spatial visualisation is of particular difficulty to students, whilst skills in spatial orientation are relatively well established. It was hypothesised that these visualisation scores would improve in the 3D modelling classes as many of the dynamic spatial processes such as mental transformation, scaling, translation between 2D shapes and 3D objects and dynamic spatial relations have been shown to be related to working in CAD environments (Ramey et al., 2020) and spatial visualisation has previously been demonstrated to be highly malleable to training (Hawes \& Ansari, 2020). This development, however, was not evident. A possible reason for this discrepancy, other than the short time period, could be that the prescriptive nature of the task (i.e. creating a spinning top using the findings from their experiments) required the students to use the program as a support for their creation of the object rather than engaging their inner mental processes. For example, if they identify that the 'body' of the top needs to be at least 5 times larger than the 'pivot point' of the bottom they can use simple algorithms and enter a figure which the CAD program will convert into the dimensions of the object. This in itself does not necessarily engage students in spatial reasoning but rather computational thinking (identifying a pattern, abstracting the unimportant parts, creating an algorithm, conducting a simulation and evaluating the efficiency of the result). Likewise, many of the students were using the coding function of the tinkerCAD program to develop their tops which did not involve them visualising the result but rather experimenting and applying prior knowledge in order to assess the results.

This focus on computational thinking was noted in the video analysis, including the design conjectures (see Sandoval, 2014 for more details) of the individual teachers before they started the lesson. Teachers could often identify spatial aspects in the expected actions of the students, but the development of spatial reasoning did not sit at the heart of their lessons and was often an addition to the focus on a technological skill. Both 3D modelling and particularly robotic engineering emphasised problem solving and utilised computational thinking extensively to the expense of particular focus on the spatial subskills. This dilution of purpose may have had an impact of the efficacy of the spatial reasoning development of the program.

A secondary goal of the study was to determine the extent to which learning in an integrated TELE could change students' attitudes towards their distinct classroom 
subjects. The results of the SAS for group 2, measured after all activities had been completed, showed no statistically significant effect on the student attitudinal profiles as a whole. As group 1 was shown to hold statistically similar CARs to group 2 this observation can be extended to this TELE more generally. This is somewhat surprising as the spatial and computational nature of the activities did require students to make use of mathematical thinking skills in solving the problems presented. However, the lack of a change in attitude is likely explained because the activities were focussed on a specific project at hand and did not require students to explicitly draw out knowledge and experiences from their specific subject classes or return the knowledge gained during the visit to the TICS to their classroom subject.

The statistically significant differences in SARs for mathematics between group 1 and group 2 post-visit are somewhat interesting. The lack of change in attitude between group 2 pre- and post-visit suggests that the differences visible in the profiles are more systemically embedded in the nature of mathematics teaching and learning at the two campuses of the school. This difference in attitude towards mathematical thinking may underly some of the differences in computational and spatial reasoning observed in the two groups in the video analysis. However, the origins of this difference in attitude require further research.

Whilst student cognitive development could have benefited from more rigorous attention to spatial reasoning, some of the affective gains during the time at TICS were quite promising. Students' observed levels of engagement when working within the TELE demonstrate the potential for similar institutes to increase engagement with STEM subjects, although longer periods of time of exposure to such activities would likely lead to improved results. Whether this novelty effect would continue requires more research, but it clearly illustrates the impact of environment on the mindset of students. The small increases in levels of self-efficacy, creativity and relevance observed in this study, while not statistically significant, may suggest that a change in learning environment and approach may encourage learners who had previously negative attitudes towards school to be more open towards the STEM fields.

\section{Future considerations}

Students involvement in the suite of learning activities needs to be examined over longer periods, to enable greater cognitive development, but this study was limited by the constraints of school logistics. Whilst engagement improved over a few sessions, spatial reasoning seemed to require a more focussed and extensive program of lessons. As the centre is new to the school, this exploratory study identified some of the possibilities for future development of technologically rich courses. The activities over the week also acted as models for digitally mediated pedagogies for each of the classes' teachers. It is therefore hoped that classroom teachers will begin to use the ideas developed by the centre in their own classes and in so doing further extend their students understandings of STEM skills such as spatial reasoning.

This study suggests that further work on the conceptualisations of how digital tools can extend and challenge students' spatial reasoning is needed. Learning tasks need 
to do more than just involve spatial reasoning; they need to centre around authentic situations which compel the students to engage in the complex processes of mental rotation, visualisation and spatial orientation (Francis et al., 2015) and develop sophisticated communication processes - through the use of spatial language. Whilst scaffolding is important, the technologies chosen for learning tasks need to avoid mitigating the mental efforts which improve the skill.

Further research is required into more extensive programs with rigorous focus on spatial skills, in order to assess whether TELEs can have significant impact on these important skills. Similarly, it is important for future studies to judge whether the changes in affect encouraged by the experiences in the TELE are persistent and have an effect on student engagement once they return to regular classrooms. Future investigations could therefore explore whether an extended time at the TICS was more meaningful in terms of affective change than weekly visits. Further research is also warranted into identifying whether these affective changes, as measured by the SAS, result in better learning and continued study in the STEM field in later years of schooling.

\section{Conclusion}

This study explored the effects TELEs have on middle years' students spatial reasoning skills, specifically, spatial visualisation, mental rotation and spatial orientation. It was found that students made positive gains in their spatial reasoning skills, from pre- to post-test. Further, whilst the SRI results did not indicate statistically significant improvement between the different spatial abilities targeted, the Student Attitudes Survey suggested that the TELE in this project has the potential to increase the engagement, self-efficacy, creativity and relevance to everyday life perceptions that the student held about STEM.

More importantly, the mixed-methods approach taken in this study has allowed a nuanced picture to emerge of with respect to the further research required. Notably, it shows a need for research that unpacks the interaction of skills such as spatial and computational thinking in TELE spaces; explores the connections between attitude, skills development, and activity design and that builds a better understanding of the impacts of timing and 'dose' time in the TELE.

Funding University of South Australia University Research Investment Performance Allocation (URIPA) grant, a National Centre for Student Equity in Higher Education (NCSEHE) grant and the Trinity Institute.

\section{Declarations}

Ethical approval UniSA Human Research Ethics Committee 202390 and 202684 as well as Trinity College Ethics.

Informed consent The principal provided informed consent for the schools involvement, and the parents provided informed consent for their children as detailed in the Ethics approval process. 


\section{References}

Andrus, B., Bar-El, D., Msall, C., Uttal, D., \& Worsley, M. (2020). Minecraft as a generative platform for analyzing and practicing spatial reasoning (pp. 297-302). Cham: Springer International Publishing.

Arcavi, A. (2003). The role of visual representations in the learning of mathematics. Educational Studies in Mathematics, 52(3), 215-241. https://doi.org/10.1023/a:1024312321077.

Attard, C., Calder, N., Holmes, K., Larkin, K., \& Trenholm, S. (2020). Teaching and learning mathematics with digital technologies. In J. Way, C. Attard, J. Anderson, J. Bobis, H. McMaster, \& K. Cartwright (Eds.), Research in Mathematics Education in Australasia 2016-2019 (pp. 319-347). Singapore: Springer Singapore.

Battista, M. T. (2007). The development of geometric and spatial thinking. In F. K. Lester (Ed.), Second handbook of research on mathematics teaching and learning : a project of the National Council of Teachers of Mathematics (pp. 843-908). Charlotte, NC: Information Age Publishing.

Blackmore, J., Bateman, D., Loughlin, J., O’Mara, J., \& Aranda, G. (2011). Research into the connection between built learning spaces and student outcomes: Literature review. East Melbourne: State of Victoria.

Bruce, C. D., Davis, B., Sinclair, N., McGarvey, L., Hallowell, D., Drefs, M., et al. (2016). Understanding gaps in research networks: using "spatial reasoning" as a window into the importance of networked educational research. [Article]. Educational Studies in Mathematics, 95(2), 143-161. https://doi. org/10.1007/s10649-016-9743-2.

Carroll, J. B. (1993). Human cognitive abilities : a survey of factor-analytic studies / John B. Carroll. Cambridge: Cambridge : Cambridge University Press.

Carvalho, L., \& Yeoman, P. (2018). Framing learning entanglement in innovative learning spaces: Connecting theory, design and practice. British Educational Research Journal, 44(6), 1120-1137. https://doi.org/10.1002/berj.3483.

Cheng, Y.-L., \& Mix, K. S. (2014). Spatial training improves children's mathematics ability. Journal of Cognition and Development, 15(1), 2-11. https://doi.org/10.1080/15248372.2012.725186.

Cochran, J. A., Cochran, Z., Laney, K., \& Dean, M. (2016). Expanding geometry understanding with 3D printing. Mathematics Teaching in the Middle School, 21(9), 534-542. https://doi.org/10.5951/ mathteacmiddscho.21.9.0534.

Community Research and Development Information Service (CORDIS) (2020). Innovative technologyenhanced learning makes STEM fashionable. https://cordis.europa.eu/article/id/415744-innovativetechnology-enhanced-learning-makes-stem-fashionable.

Connor, J. M., \& Serbin, L. A. (1980). Mathematics, visual-spatial ability, and sex roles. Final report. Washington DC: National Institute of Education (DHEW).

Cutting, C. (2019). Re-thinkingfraction instruction in primary school: The case for an alternative approach inthe early years. In G. Hine, S. Blackley, \& A. Cooke (Eds.), Mathematicseducation research: Impacting practice Proceedings of the 42nd annualconference of the Mathematics Education Research Group of Australasia,Perth, (pp. 276-283). MERGA.

Dekkers, J., \& de Laeter, J. (2001). Enrolment trends in school science education in Australia. International Journal of Science Education, 23(5), 487-500.

Dekkers, J., De Laeter, J. R., \& Malone, J. A. (1986). Upper secondary school science and mathematics enrolment patterns in Australia, 1970-1985 / John Dekkers, John R. De Laeter and John A. Malone: Bentley, W.A. : Science and Mathematics Education Centre, Western Australian Institute of Technology?

Ekstrom, R. B., French, J. W., Harman, H. H., \& Dermen, D. (1976). Manual for kit of factor-referenced cognitive tests. Princeton, New Jersey: Educational Testing Service.

Fowler, S., O'Keeffe, L., Cutting, C., \& Leonard, S. N. (2019). The mathematics proficiencies: A doorway into spatial thinking. Australian Primary Mathematics Classroom, 24(1), 36-40.

Francis, K., Khan, S., \& Davis, B. (2015). Enactivism, Spatial Reasoning and Coding. [journal article]. Digital Experiences in Mathematics Education, 2(1), 1-20. https://doi.org/10.1007/s40751015-0010-4.

Guillot, A., Hoyek, N., Louis, M., \& Collet, C. (2012). Understanding the timing of motor imagery: Recent findings and future directions. International Review of Sport and Exercise Psychology, 5(1), 3-22. https://doi.org/10.1080/1750984X.2011.623787. 
Harris, D., Logan, T., \& Lowrie, T. (2020). Unpacking mathematical-spatial relations: Problem-solving in static and interactive tasks. Mathematics Education Research Journal. https://doi.org/10.1007/ s13394-020-00316-Z.

Hawes, Z., \& Ansari, D. (2020). What explains the relationship between spatial and mathematical skills? A review of evidence from brain and behavior. Psychonomic Bulletin \& Review, 27(3). https://doi. org/10.3758/s13423-019-01694-7.

Johnson-Glenberg, M. C. (2019). The necessary nine: Design principles for embodied VR and active stem education. In P. Díaz, A. Ioannou, K. K. Bhagat, \& J. M. Spector (Eds.), Learning in a Digital World: Perspective on Interactive Technologies for Formal and Informal Education (pp. 83-112). Singapore: Springer Singapore.

Kennedy, J., Lyons, T., \& Quinn, F. (2014). The continuing decline of science and mathematics enrolments in Australian high schools. Teaching Science, 60(2), 34-46.

Kennedy, J., Quinn, F., \& Taylor, N. (2016). The school science attitude survey: a new instrument for measuring attitudes towards school science. International Journal of Research \& Method in Education, 39(4), 422-445. https://doi.org/10.1080/1743727x.2016.1160046.

Kennedy, J., Quinn, F., \& Lyons, T. (2018). The keys to STEM: Australian year 7 students' attitudes and intentions towards science, mathematics and technology courses. Research in Science Education. https://doi.org/10.1007/s11165-018-9754-3.

Lakoff, G., \& Núñez, R. E. (2001). Where mathematics comes from: How the embodied mind brings mathematics into being. Journal for Research in Mathematics Education, 32(3), 330.

Lieban, D., \& Lavicza, Z. (2019). Dissecting a cube as a teaching strategy for enhancing students' spatial reasoning: Combining physical and digital resources. In Bridges 2019 Conference Proceedings (pp. 319-326): Tessellations Publishing.

Linn, M. C., \& Petersen, A. C. (1985). Emergence and characterization of sex differences in spatial ability: A meta-analysis. Child Development, 56(6), 1479-1498. https://doi.org/10.2307/1130467.

Leonard, S. N., Fitzgerald, R. N., Bacon, M., \& Munnerley, D. (2017). Mapping next generation learning spaces as a designed quality enhancement process. Quality in Higher Education, 23(2), 168-182. https://doi.org/10.1080/13538322.2017.1358955.

Leonard, S. N., \& Fitzgerald, R. N. (2018). Holographic learning: A mixed reality trial of Microsoft HoloLens in an Australian secondary school. Research in Learning Technology, 26(0), 1-12. https:// doi.org/10.25304/rlt.v26.2160.

Logan, T., \& Lowrie, T. (2017). Gender perspectives on spatial tasks in a national assessment: a secondary data analysis. Research in Mathematics Education, 19(2), 199-216. https://doi. org/10.1080/14794802.2017.1334577.

Lohman, D. F. (1996). Spatial ability and g. In I. Dennis \& P. Tapsfield (Eds.), Human abilities: Their nature and measurement (pp. 96-116). Inc: Lawrence Erlbaum Associates.

Lowrie, T., \& Jorgensen, R. (2018). Equity and spatial reasoning: reducing the mathematical achievement gap in gender and social disadvantage. Mathematics Education Research Journal, 30(1), 65-75. https://doi.org/10.1007/s13394-017-0213-7.

Lowrie, T., \& Logan, T. (2018). The interaction between spatial reasoning constructs and mathematics understandings in elementary classrooms. In K. S. Mix \& M. T. Battista (Eds.), Visualizing Mathematics: The Role of Spatial Reasoning in Mathematical Thought (pp. 253-276). Cham: Springer International Publishing.

Lowrie, T., Logan, T., Harris, D., \& Hegarty, M. (2018). The impact of an intervention program on students' spatial reasoning: student engagement through mathematics-enhanced learning activities. [journal article]. Cognitive Research: Principles and Implications, 3(1), 50. https://doi.org/10.1186/ s41235-018-0147-y.

Lowrie, T., Logan, T., \& Hegarty, M. (2019). The influence of spatial visualization training on students' spatial reasoning and mathematics performance. Journal of Cognition and Development, 20(5), 729-751. https://doi.org/10.1080/15248372.2019.1653298.

Matthews, K. E., Andrews, V., \& Adams, P. (2011). Social learning spaces and student engagement. Higher Education Research and Development, 30(2), 105-120. https://doi.org/10.1080/07294360. 2010.512629.

McGee, M. G. (1979). Human spatial abilities: Psychometric studies and environmental, genetic, hormonal, and neurological influences. Psychological Bulletin, 86(5), 889-918. https://doi. org/10.1037/0033-2909.86.5.889. 
Mulligan, J., Woolcott, G., Mitchelmore, M., \& Davis, B. (2017). Connecting mathematics learning through spatial reasoning. Mathematics Education Research Journal, 30(1), 77-87. https://doi. org/10.1007/s13394-017-0210-x.

National Research Council. (2006). learning to think spatially: geographic information systems (GIS) as a support system in the $k-12$ curriculum. Washington, DC: National Academies Press.

Ontario Ministry of Education. (2008). Geometry and Spatial Sense, Grades 4 to 6: A Guide to Effective Instruction in Mathematics, Kindergarten to Grade 6: Queen's Printer for Ontario.

Pietropaolo, S., \& Crusio, W. E. (2012). Learning spatial orientation. In N. M. Seel (Ed.), Encyclopedia of the Sciences of Learning (pp. 1969-1971). Boston, MA: Springer, US.

Rafi, A., Samsudin, K. A., \& Said, C. S. (2008). Training in spatial visualization: The effects of training method and gender. Journal of Educational Technology \& Society, 11(3), 127-140.

Ramey, K. E., Stevens, R., \& Uttal, D. H. (2020). In-FUSE-ing STEAM learning with spatial reasoning: Distributed spatial sensemaking in school-based making activities. Journal of Educational Psychology, 112(3), 466-493. https://doi.org/10.1037/edu0000422.

Ramful, A., \& Lowrie, T. Spatial visualisation and cognitive style: How do gender differences play out? In Mathematics Education in the Margins: Annual conference of the Mathematics Education Research Group of Australasia, Sunshine Coast, Australia, 2015 (pp. 1-8): MERGA.

Ramful, A., Lowrie, T., \& Logan, T. (2017). Measurement of spatial ability: Construction and validation of the spatial reasoning instrument for middle school students. Journal of Psychoeducational Assessment, 35(7), 709-727. https://doi.org/10.1177/0734282916659207.

Reilly, D., Neumann, D. L., \& Andrews, G. (2017). Gender differences in spatial ability: Implications for STEM education and approaches to reducing the gender gap for parents and educators. In M. S. Khine (Ed.), Visual-spatial Ability in STEM Education: Transforming Research into Practice (pp. 195-224). Cham: Springer International Publishing.

Sandoval, W. (2014). Conjecture mapping: An approach to systematic educational design research. Journal of the Learning Sciences, 23(1), 18-36. https://doi.org/10.1080/10508406.2013.778204.

Scottish Funding Council. (2006). Spaces for learning: A review of learning spaces in further and higher educaiton.

Sebena, C. (2017). Early child spatial development: A teaching experiment with programmable robots. In G. Aldon, F. Hitt, L. Bazzini, \& U. Gellert (Eds.), Mathematics and Technology A C.I.E.A.E.M. Sourcebook (pp. 13-30). Cham: Springer International Publishing : Imprint: Springer.

Shepard, R. N., \& Metzler, J. (1971). Mental rotation of three-dimensional objects. Science, 171(3972), 701-703. https://doi.org/10.1126/science.171.3972.701.

Sinclair, N., Bartolini Bussi, M. G., de Villiers, M., Jones, K., Kortenkamp, U., Leung, A., et al. (2016). Recent research on geometry education: an ICME-13 survey team report. ZDM Mathematics Education, 48(5), 691-719. https://doi.org/10.1007/s11858-016-0796-6.

Singer, B., \& Shafer, K. G. (2018). Exploring spatial reasoning with Sketchup make. Teaching Children Mathematics, 25(1), 46. https://doi.org/10.5951/teacchilmath.25.1.0046.

Smith, M. K., Jones, F. H. M., Gilbert, S. L., \& Wieman, C. E. (2013). The Classroom Observation Protocol for Undergraduate STEM (COPUS): A new instrument to characterize university STEM classroom practices. CBE Life Sciences Education, 12(4), 618-627. https://doi.org/10.1187/ cbe.13-08-0154.

South Australia Department for Education. (2020). STEM Works. https://www.education.sa.gov.au/sitesand-facilities/stem-works.

Sorby, S. A., \& Panther, G. C. (2020). Is the key to better PISA math scores improving spatial skills? Mathematics Education Research Journal. https://doi.org/10.1007/s13394-020-00328-9.

Stieff, M., \& Uttal, D. (2015). How much can spatial training improve STEM achievement? Educational Psychology Review, 27(4), 607-615. https://doi.org/10.1007/s10648-015-9304-8.

Tartre, L. A. (1990). Spatial orientation skill and mathematical problem solving. Journal for Research in Mathematics Education, 21(3), 216-229. https://doi.org/10.2307/749375.

Ulan, D., Pecen, R. R., Yildiz, F., \& Shah, A. (2018). Development of virtual environment to introduce spatial reasoning to first- and second-year engineering students. Atlanta: American Society for Engineering Education-ASEE.

Uttal, D. H., Meadow, N. G., Tipton, E., Hand, L. L., Alden, A. R., Warren, C., et al. (2013). The malleability of spatial skills: A meta-analysis of training studies. Psychological Bulletin, 139(2), 352-402. https://doi.org/10.1037/a0028446.

Venturini, M., \& Sinclair, N. (2017). Designing assessment tasks in a dynamic geometry environment. In A. Leung, \& A. Baccaglini-Frank (Eds.), Digital Technologies in Designing Mathematics Education 
Tasks (pp. 77-98, Mathematics Education in the Digital Era). Cham: Springer International Publishing.

Wai, J., Lubinski, D., \& Benbow, C. P. (2009). Spatial ability for STEM domains: Aligning over 50 years of cumulative psychological knowledge solidifies its importance. Journal of Educational Psychology, 101(4), 817-835. https://doi.org/10.1037/a0016127.

Waldrip, B., Cox, P., \& Yu, J. J. (2014). Quantitative research on personalising learning and wellbeing in open-plan up-scaled learning communities; Challenges in researching attempts to personalise learning. In V. Prain, P. Cox, Craig Deed, D. Edwards, C. Farrelly, M. Keeffe, et al. (Eds.), Adapting to Teaching and Learning in Open-Plan Schools (pp. 19-41). Rotterdam: Sense.

Woolcott, G., Chamberlain, D., Keast, R., \& Farr-Wharton, B. (2016). Engagement and undergraduate retention: Social network analysis and student social ecologies. Research in Higher Education Journal, 31, 1-35.

Woolcott, G., Logan, T., Marshman, M., Ramful, A., Whannell, R., \& Lowrie, T. (2020). The re-emergence of spatial reasoning within primary years mathematics education. In J. Way, C. Attard, J. Anderson, J. Bobis, H. McMaster, \& K. Cartwright (Eds.), Research in Mathematics Education in Australasia 2016-2019 (pp. 245-268). Singapore: Springer Singapore.

Publisher's Note Springer Nature remains neutral with regard to jurisdictional claims in published maps and institutional affiliations.

\section{Authors and Affiliations}

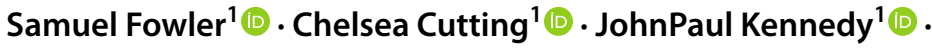 Simon N. Leonard ${ }^{1}$ (1) - Florence Gabriel ${ }^{1}$ (1) - Wayne Jaeschke ${ }^{2}$ (I)}

Chelsea Cutting

Chelsea.Cutting@unisa.edu.au

JohnPaul Kennedy

John.Kennedy@unisa.edu.au

Simon N. Leonard

Simon.Leonard@unisa.edu.au

Florence Gabriel

Florence.Gabriel@unisa.edu.au

Wayne Jaeschke

jaeschwa@trinity.sa.edu.au

1 Education Futures, University of South Australia, Adelaide, South Australia, Australia

2 Trinity College Gawler, Adelaide, South Australia, Australia 